\title{
Successful repair of an atrial septal defect associated with right to left shunting
}

\author{
KENNETH F HOSSACK, * JOHN C TEWKSBURY, $†$ LYNNE M REID† \\ From the ${ }^{\star}$ Department of Medicine, Division of Cardiology, University of Colorado Health Sciences Center, \\ Denver, Colorado; and †Department of Pathology, The Children's Hospital, Boston, Massachusetts, USA
}

SUMMARY An atrial septal defect was successfully repaired in a young woman despite the presence of pulmonary hypertension and right to left shunting. Before repair both isoprenaline infusion and $100 \%$ inspired oxygen produced significant falls in pulmonary artery pressure and pulmonary vascular resistance. A lung biopsy specimen at operation indicated a considerable decrease in the concentration of parenchymal pulmonary arteries and an absence of intimal fibrosis or medial hypertrophy.

Pulmonary artery banding performed in infancy, as part of the management of a ventricular septal defect, may have contributed to the underdevelopment of the pulmonary vascular tree. The reduced number of pulmonary arteries is a possible explanation for the pulmonary hypertension.

It is uncommon for an isolated atrial septal defect to be associated with right to left shunting unless severe pulmonary hypertension is present. Operation is usually not recommended in such patients. We report a young patient with an atrial septal defect associated with pulmonary hypertension and right to left shunting who underwent successful repair. We believe that underdevelopment of the pulmonary tree, which was shown by lung biopsy, was associated with a pre-existing ventricular septal defect and pulmonary artery banding.

\section{Case report}

As an infant the patient presented with heart failure and a murmur was detected. She was acyanotic and at catheterisation at the age of nine months the atrial septum was crossed and a left to right shunt at the ventricular level was shown. Pulmonary artery pressure was not measured. Right and left ventricular systolic pressures were $51 \mathrm{~mm} \mathrm{Hg}$ and $80 \mathrm{~mm} \mathrm{Hg}$ respectively. Medical management was recommended and catheterisation (at age two) confirmed a left to right shunt at the ventricular level and pulmonary hypertension (table 1). Infusion of tolazoline hydrochloride resulted in a small fall in pulmonary resis-

Requests for reprints to Dr Kenneth F Hossack, Department of Medicine, Division of Cardiology, 777 Bannock Street, Box \#A009, Denver, Colorado 80204, USA. tance and an increase in the pulmonary systemic flow ratio. Pulmonary artery banding was performed.

When she was three and a half years old repeat catheterisation indicated a bi-directional shunt at the ventricular level. There was a $20-36 \mathrm{~mm} \mathrm{Hg}$ peak systolic gradient across the region of the band and the distal pulmonary artery pressure was raised (64/30 $\mathrm{mm} \mathrm{Hg}$ ). The ventricular septal defect was closed and the band removed; apart from several early postoperative episodes of cyanosis the subsequent course was uneventful.

At the age of 19, when she was 20 weeks pregnant, the patient presented with haemoptysis, and an initial diagnosis of pulmonary embolism was excluded by pulmonary angiography. A limited study of the right heart showed pulmonary artery pressure of $55 / 22$ (mean $35 \mathrm{~mm} \mathrm{Hg}$ ). Bi-directional shunting at the atrial level with a small net right to left shunt was detected. Table 1 does not include the results of this study. The arterial oxygen saturation was $88 \%$ on room air. Subsequent bronchoscopy showed prominent submucosal vessels in the bronchi and it was thought that rupture of these vessels had caused the haemoptysis. Physical findings included an active right ventricle on palpation, wide fixed splitting of the second heart sound, and a soft ejection systolic murmur along the upper left sternal border. There was no evidence of clubbing. The electrocardiogram showed sinus rhythm, right axis deviation, and right ventricular hypertrophy. Chest $x$ ray showed a normal sized heart and normal vascular pattern. A cross 

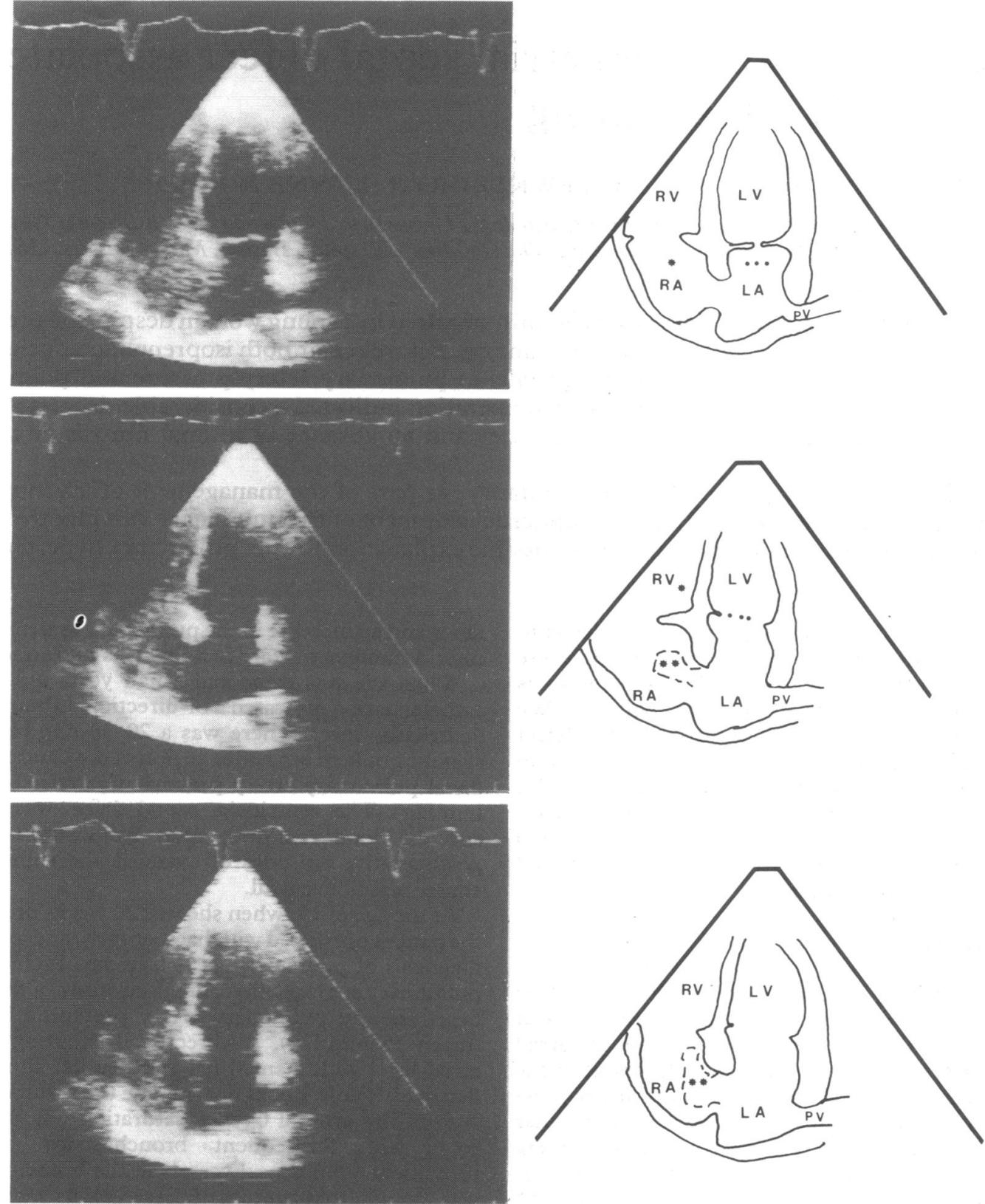

Fig 1 Sequence of cross sectional images recorded from the apical four chamber acoustic window and corresponding line drawings of a saline injection showing a bi-directional shunt at atrial level. Top panel: this systolic frame shows deviation of the interatrial septum toward the left atrium and microbubbles (*) filling the right atrium and also the left atrium ( $\star \star \star)$. Middle panel: this shows a diastolic frame with microbubbles in the orifice of the mitral valve ( $\star \star \star)$ and entering the left ventricle. A small area of washout is seen in the right atrium $(\star \star)$. Bottom panel: this is the next frame in the cycle and the negative area in the right atrium is larger $(\star \star)$. $L A$, left atrium; $L V$, left ventricle; $P V$, pulmonary vein; $R A$, right atrium; $R V$, right ventricle. 
Table 1 Results of cardiac catheterisation

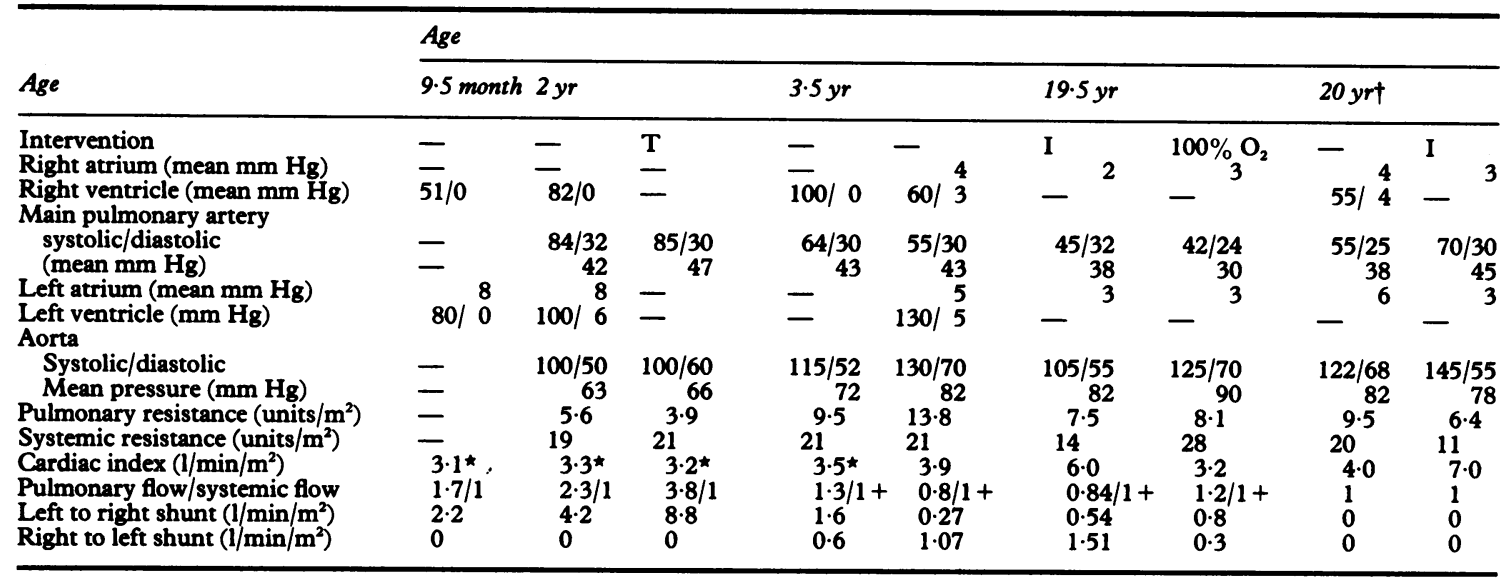

^Assuming an oxygen consumption of $120 \mathrm{ml} / \mathrm{min} / \mathrm{m}^{2}$. $†$ Six months after closure of the atrial septal defect. I, isoprenaline; T, tolazoline hydrochloride; +, bi-directional shunt.

sectional echocardiographic study with saline injection showed bi-directional shunting at the atrial level (fig 1). Because of hypoxia the patient was prescribed supplemental nasal oxygen which eliminated the arterial desaturation. The patient tolerated vaginal delivery at 34 weeks' gestation. The premature infant was well at discharge.

After delivery, repeat catheterisation (table 1) showed moderate pulmonary hypertension, and isoprenaline infusion reduced the pulmonary vascular resistance from 13.8 units $/ \mathrm{m}^{2}$ to 7.5 units $/ \mathrm{m}^{2}$. The arterial oxygen saturation on room air was $83 \%$. There was a bi-directional shunt at the atrial level with a net right to left shunt. The pulmonary systemic flow ratio increased from 0.8 to 0.84 with isoprenaline infusion. When the patient breathed $100 \%$ oxygen pulmonary artery pressure fell and the net shunt was left to right. Contrast injection in the

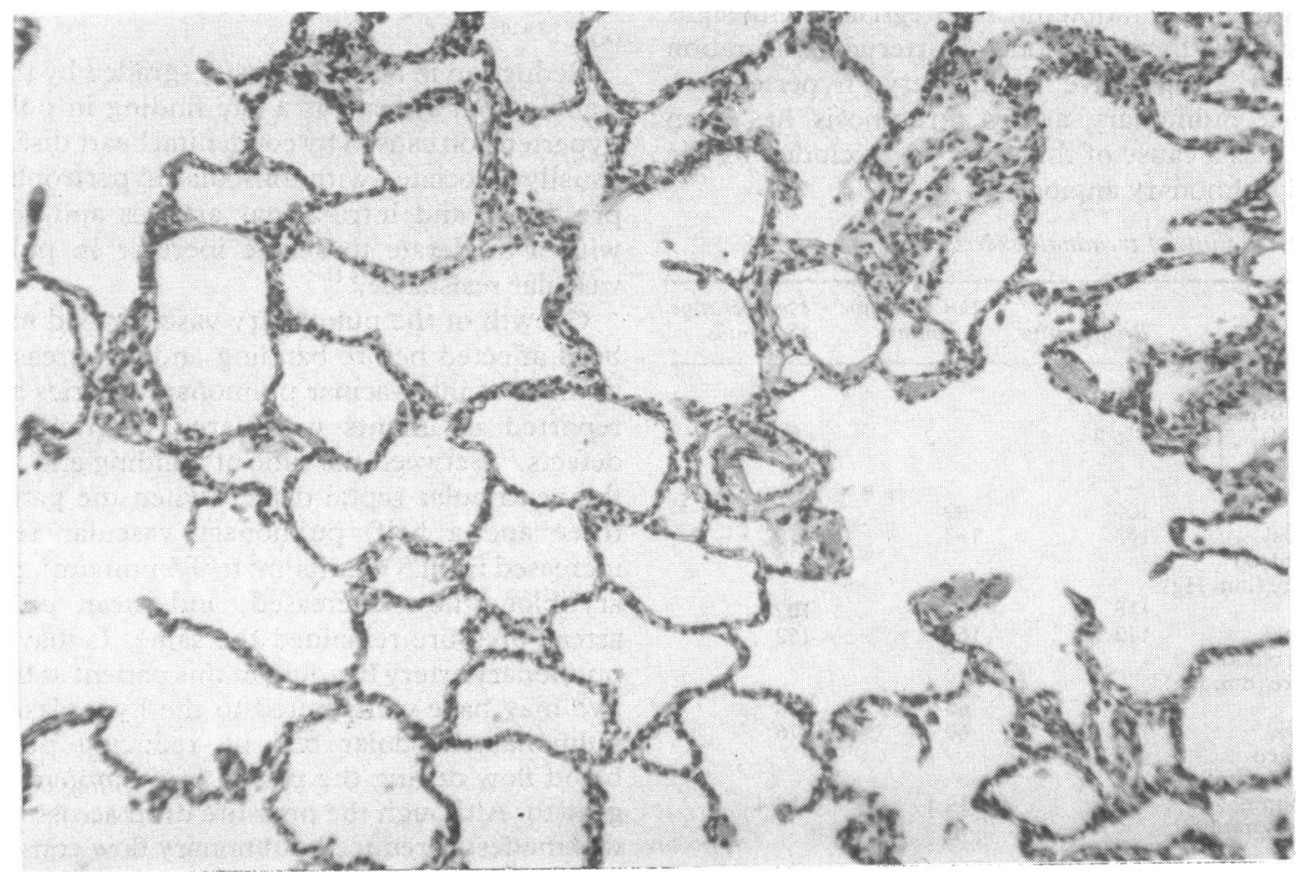

Fig $2 A$ section of the lung biopsy specimen showing the paucity of parenchymal arteries. Only one artery is seen centrally. 
inferior vena cava showed flow across the interatrial septum and left to right shunting on recirculation. Left ventricular cineangiography indicated an intact ventricular septum. A $1 \times 2 \mathrm{~cm}$ atrial septal defect was surgically closed.

A lung biopsy (fig 2) performed at operation showed that the density of the small arteries was reduced; the ratio of pulmonary arteries to alveoli was 1:18 (normal for this age, 1:6). The ratio was assessed by examining a number of fields although only one artery is shown in the figure. Intra-acinar arteries appeared to be dilated but without evidence of muscular hypertrophy. Pre-acinar arteries showed minimal muscular hypertrophy without intimal lesions. The alveolar walls were delicate without fibrosis and the radial alveolar count of 10 was within the normal range.

Catheterisation (table 1) performed six months after operation indicated no evidence of shunting and the pulmonary vascular resistance fell from 13.8 units $/ \mathrm{m}^{2}$ before operation to 9.5 units $/ \mathrm{m}^{2}$ after operation. The results of exercise testing performed six months and 18 months after operation showed improvement in exercise capacity (table 2). Postoperatively there was no significant desaturation with exercise.

\section{Discussion}

The initial presentation during pregnancy with signs of pulmonary hypertension and arterial desaturation suggested progressive pulmonary hypertension. Proximal pulmonary artery thrombosis has been reported as a cause of this ${ }^{1}$ and was excluded by the normal pulmonary angiogram.

Table 2 Results of treadmill exercise testing

\begin{tabular}{|c|c|c|c|}
\hline & Preoperative & $\begin{array}{l}\text { Postoperative } \\
6 \text { months }\end{array}$ & $\begin{array}{l}\text { Postoperative } \\
18 \text { months }\end{array}$ \\
\hline \multicolumn{4}{|l|}{$\begin{array}{l}\text { Exercise duration } \\
\text { (min) (Bruce }\end{array}$} \\
\hline $\begin{array}{l}\text { Heart rate } \\
\text { (beats/min): } \\
\text { Rest } \\
\text { Maximal }\end{array}$ & $\begin{array}{l}100 \\
163\end{array}$ & $\begin{array}{r}82 \\
163\end{array}$ & $\begin{array}{r}64 \\
172\end{array}$ \\
\hline $\begin{array}{l}\text { Systolic blood } \\
\text { pressure (mm Hg): } \\
\text { Rest } \\
\text { Maximal }\end{array}$ & $\begin{array}{l}118 \\
142\end{array}$ & $\begin{array}{l}110 \\
160\end{array}$ & $\begin{array}{l}102 \\
152\end{array}$ \\
\hline $\begin{array}{l}\text { Diastolic blood } \\
\text { pressure (mm } \mathrm{Hg}) \text { : } \\
\text { Rest } \\
\text { Maximal }\end{array}$ & $\begin{array}{l}64 \\
54\end{array}$ & $\begin{array}{l}60 \\
60\end{array}$ & $\begin{array}{l}68 \\
76\end{array}$ \\
\hline $\begin{array}{l}\text { Peak oxygen } \\
\text { consumption } \\
(\mathrm{ml} / \mathrm{kg} / \mathrm{min})\end{array}$ & 12.5 & $19 \cdot 1$ & $18 \cdot 4$ \\
\hline $\begin{array}{l}\text { Oxygen saturation } \\
(\%): \\
\text { Rest } \\
\text { Maximal }\end{array}$ & $\begin{array}{l}93 \\
79\end{array}$ & $\begin{array}{l}97 \\
94\end{array}$ & - \\
\hline
\end{tabular}

After closure of a ventricular septal defect most infants show resolution of pulmonary hypertension; however, a few became worse. Before the pulmonary artery banding the pulmonary vascular resistance was raised and there was further increase after the band was placed. The postoperative pulmonary resistance at the age of 20 was very similar to that at the age of three and a half.

The pulmonary vascular resistance $\left(13.8 \mathrm{units} / \mathrm{m}^{2}\right)$ and arterial desaturation are adverse prognostic factors for operation. ${ }^{2}$ The reduction in resistance with isoprenaline and when $100 \%$ oxygen was breathed suggested considerable pulmonary vascular reactivity. The value of 7.5 units $/ \mathrm{m}^{2}$ was similar to that at which others recommend closure of a ventricular septal defect associated with pulmonary hypertension. ${ }^{3}$ However, a lower resistance value can be associated with histological evidence of severe pulmonary vascular disease. ${ }^{4}$

The development of the alveolar region starts prenatally. The number of alveoli increases until about eight years of age and the growth of intraacinar arteries follows that of the alveoli. ${ }^{5-7}$ The period of most rapid growth is before the age of three. ${ }^{78}$ The density of small arteries increases more than alveolar density such that the ratio of arteries to alveoli at birth is $1: 20$, but by adulthood it is $1: 6 .{ }^{9}$ Muscularisation of these distal arteries lags, and the adult pattern of muscularisation as related to size does not develop until late childhood or early adulthood. 57910

Reduction in arterial density (graded by the ReidRabinovitch system) is a late finding in pulmonary hypertension caused by congenital heart disease. It is usually associated with muscular hypertrophy of the pre-acinar and intra-acinar arteries and correlates with a moderate to severe increase in pulmonary vascular resistance. ${ }^{911}$

Growth of the pulmonary vascular bed may have been affected before banding and a decrease in the number of intra-acinar pulmonary arteries has been reported in infants with large ventricular septal defects. ${ }^{12}$ Between the time of banding and repair of the ventricular septal defect (when the patient was three and a half) pulmonary vascular resistance increased from 5.6 units $/ \mathrm{m}^{2}$ to 9.5 units $/ \mathrm{m}^{2}$, pulmonary blood flow decreased, and mean pulmonary artery pressure remained the same. It may be that pulmonary artery banding in this patient at the age of two may have contributed to the hypoplasia of the pulmonary vascular bed by reducing pulmonary blood flow during the period of pulmonary arterial growth. Although the pressure drop across the band was modest it reduced pulmonary flow considerably and caused a net right to left shunt. In animal models banding of the pulmonary artery decreased the 
density of the parenchymal arteries. ${ }^{13}$ A similar decrease in density of the parenchymal arteries has been found in neonates with pulmonary atresia. ${ }^{14}$ Occlusion of the alveolar wall arteries was detected in several patients with pulmonary hypertension associated with congenital heart disease, and it was suggested that this helped explain the reduction in intra-acinar arterial numbers. ${ }^{15} \mathrm{~A}$ reduction in distending pressure was suggested as a possible mechanism for this. In the patient we studied the banding reduced systolic pulmonary artery pressure from 85 to $64 \mathrm{~mm} \mathrm{Hg}$ while pulmonary vascular resistance increased. There are not sufficient abnormalities in the pre-acinar arteries to explain the persistent pulmonary hypertension, and the intraacinar arteries seem to be morphologically normal without an abnormal degree of muscularisation. This suggests that the persistent pulmonary hypertension is secondary to hypoplasia of the pulmonary vascular bed.

Most patients with an atrial septal defect associated with severe pulmonary hypertension will not benefit from closure. However, a few like this patient, who show a reduction in pulmonary hypertension with pharmacological agents may be candidates for closure. A preoperative lung biopsy may be helpful in deciding on management. Recognition of the histological pattern of reduced parenchymal arteries on lung biopsy may help to explain pulmonary hypertension. The lack of intimal fibrosis or medial hypertrophy in the pulmonary arteries is unusual given the degree of pulmonary hypertension.

\section{References}

1 Schamroth CL, Sareli P, Pocock WA, et al. Pulmonary arterial thrombosis in secundum atrial septal defect. Am J Cardiol 1987;60:1152-6.

2 Steele PM, Fuster V, Cohen M, Ritter DG, McGoon DC. Isolated atrial septal defect with pulmonary vascular obstructive disease-long term follow-up and prediction of outcome after surgical correction. Circulation 1987;76:1037-42.

3 Neutze JM, Ishikawa T, Clarkson PM, Calder AL, Barratt-Boyes BG, Kerr AR. Assessment and followup of patients with ventricular septal defect and elevated pulmonary vascular resistance. Am J Cardiol 1989;63:327-31.

4 Bush A, Busst CM, Haworth SG, et al. Correlations of morphology, pulmonary vascular resistance, and outcome in children with congenital heart disease. Br Heart $J$ 1988;59:480-5.

5 Reid LM. Lung growth in health and disease. $\mathrm{Br} J$ Dis Chest 1984;78:113-34.

6 Dunhill MS. Postnatal growth of lung. Thorax 1962;17: 329-33.

7 Davies G, Reid L. Growth of the alveoli and pulmonary arteries in childhood. Thorax 1970;25:669-81.

8 Hislop AA, Wigglesworth JS, Desai R. Alveolar development in the human fetus and infant. Early Hum Dev 1986;13:1-11.

9 Rabinovitch M, Haworth SG, Castaneda AR, Nadas AS, Reid LM. Lung biopsy in congenital heart disease: a morphometric approach to pulmonary vascular disease. Circulation 1978;58:1107-22.

10 Reid L, Meyrick B. Microcirculation: definition and organization at tissue level. Presented at Conference on Mechanisms of Lung Microvascular Injury. Ann NY Acad Sci 1982;384:3-20.

11 Rabinovitch M, Reid LM. Quantitative structural analysis of the pulmonary vascular bed in congenital heart defects. Cardiovasc Clin 1980;11(2):149-69.

12 Haworth SG, Sauer U, Bühlmeyer K, Reid L. Development of the pulmonary circulation in ventricular septal defect. A quantitative structural study. Am J Cardiol 1977;40:781-8.

13 Rabinovitch M, Konstam MA, Gamble WJ, et al. Changes in pulmonary blood flow affect vascular response to chronic hypoxia in rats. Circ Res 1983; 52:432-41.

14 Haworth SG, Reid L. Quantitative structural study of pulmonary circulation in the newborn with pulmonary atresia. Thorax 1977;32:129-33.

15 Haworth SG, Hall SM. Occlusion of intra-acinar pulmonary arteries in pulmonary hypertensive congenital heart disease. Int J Cardiol 1986;13:207-17. 